\title{
استراتيجيات مواجهة الضغوط عند المسنين المصابين بالسرطان
}

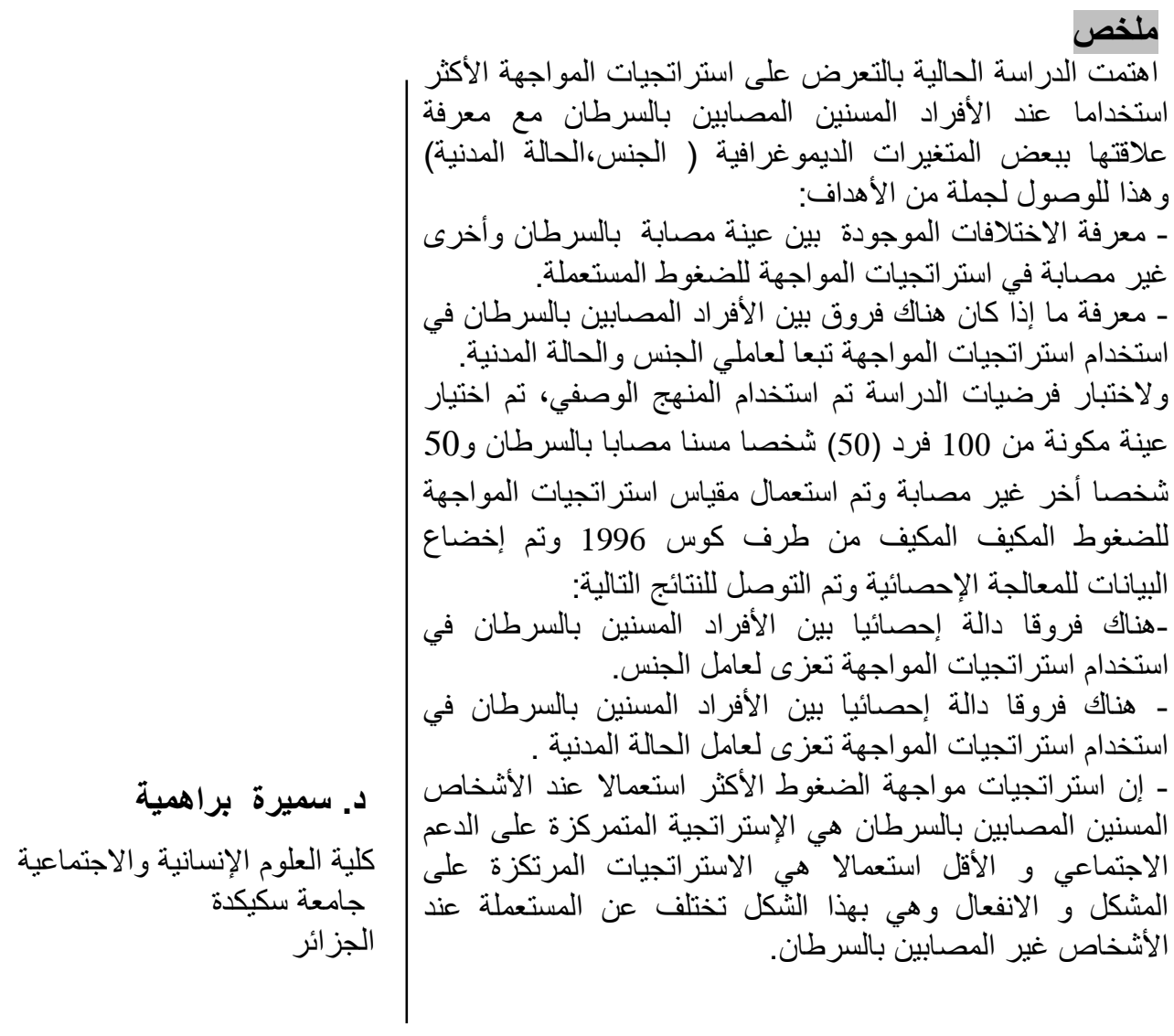

\section{مقدمة - ( - مقة}

هُمر الإنسان في دورة الحياة بمر احل عمرية مختلفة فمن الطفولة إلى المر اهقة ثم إلى مرحلة الطية

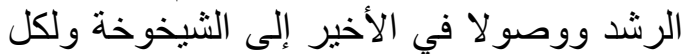

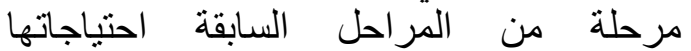
ومتطلباتها ومجمو عة من التغير ات التي تر افقها

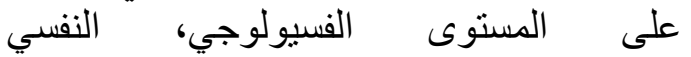
و الاجتماعي. وفي هذا المقال البحثي نتوقف عند

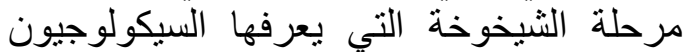

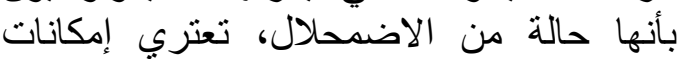

\section{Abstract}

This study examines the confrontation / adaptation strategies (or adaptation) most commonly used by the elderly cancer patients to face stress and their relationship with some demographic variables of gender and family status. The first purpose of the study is to determine the difference that may exist between a sample of cancer patients and a healthy sample with 
التوافق الثخصي و الاجتماعي للفرد فتقل قدرته

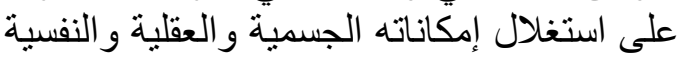

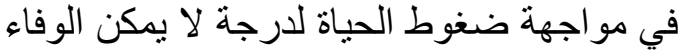
الكامل بمتطلبات البيئة، أو تحقيق قدر مناسب لإن التباء

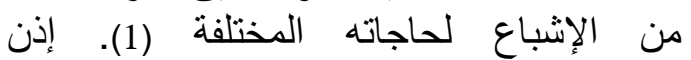
فالثيخوخة مرحلة عمرية حرجة يكون فيها الفرد اجتاز جزءا غير هين من حئه حياته وخاص

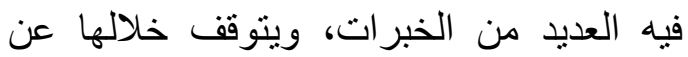
العمل ويبقى دون ممارسة نشاط مهني ، فيشعر المسن بفراغ رهيب مع عجز عن تدبر شؤونها

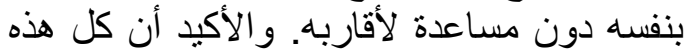

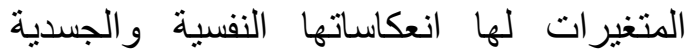

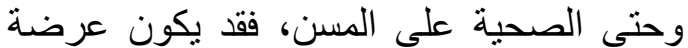
للإصابة بعديد من الأمر اض السيكوسوماتية والتي كثيرا ما تكون في خلقية أسباب حدوثنها

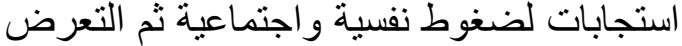

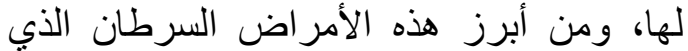
يعد أحد أهم أسباب الوفيات في العالم سنة 2007 و هذا بنسبة 13 \% (2). وتترك الإصابة بمرض السرطان وما يسبيه آلام جسدية ومعنوية نظر اللعزلة الاجتماعية التي يجد فيها

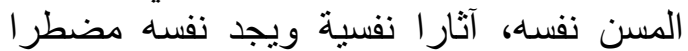
لمو اجهته ومحاولة التعايش معانه. ويرى كل من لازاروس ومن فولكمان Lazarus et Folkman 1984 إلى المجهودات العقلية و السلوكية للسبطرة، أو الو regards to strategies used in managing stress. The second purpose is to determine whether there is a difference among elderly cancer patients with regards to gender and family status. To examine the research variables, a descriptive method was used with a sample of 100 individuals (50 elderly cancer patients and 50 healthy persons). Cousson (1996) adapted Model of strategies adjustment was used and the data were statistically reviewed by the SPSS program. The results show that there are significant statistical differences among the sample of elderly cancer patients in using adaptation strategies with regards to gender, and significant statistical differences among the same sample in using adaptation strategies with regards to family status; Furthermore, the results show that, contrary to the strategies used by the healthy sample, the most commonly used strategy among the elderly cancer patient sample is relying on social support while the least used strategies are focusing on the problem and emotion.

Keywords: coping strategies (or adaptations) - managing stresscancer-elderly patients

\footnotetext{
تحمل المطالب الخارجية أو الداخلية التي تنتج عن موقف ضاغطر 3).

ويقسم لازاروس وفولكمان استراتيجيات التكيف إلى نوعين هما استراتيجيات مرتكزة على المشكلة، ويستخدم فيها مهار ات التخطبط و التقبل و إعادة البناء و التشكيل

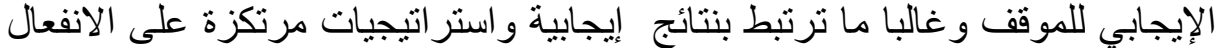

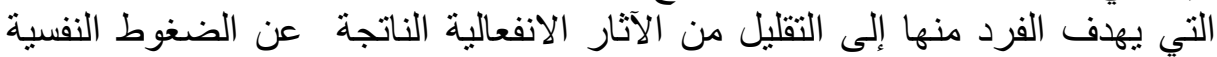

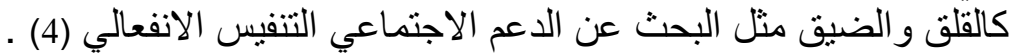




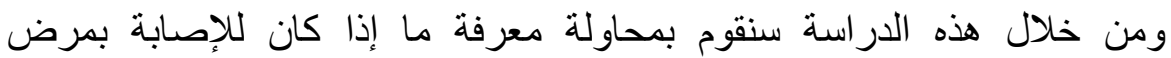

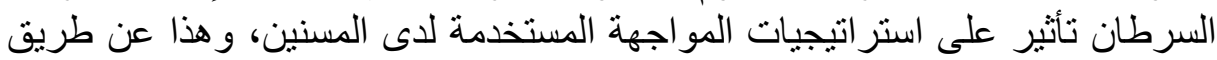

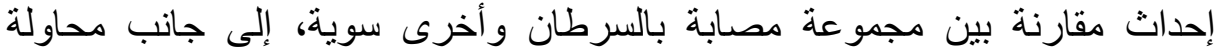

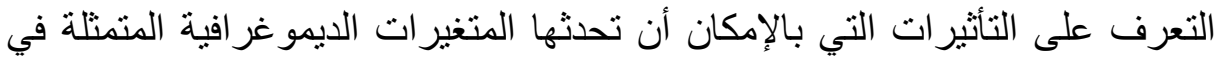

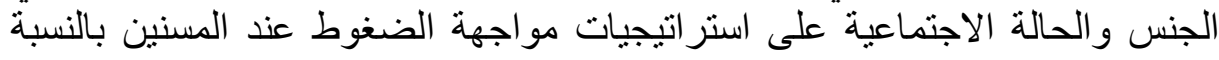

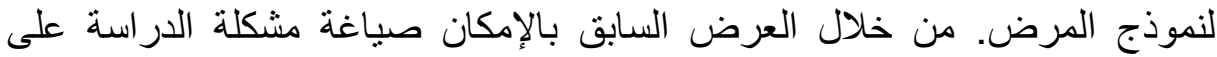
- - لهو التالي: يختلف المسنون المصابون بالسرطان عن غير المصابين في استعمال

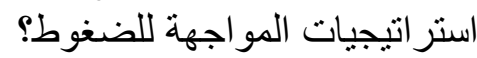
- هل هنالك فروق في استعمال استراتجيات المواجهة عند الأشخاص المسنين المصابين بالسرطان تبعا لمتغير الجنس؟ فئس الفئ

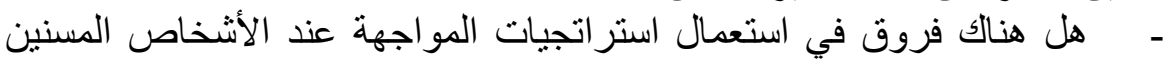
المصابين بالسرطان تبعا لمتغير الحالة الاجتماعية؟ فئج

$$
\text { فرضيات الاراسة : }
$$

1- توجد فروف دالة إحصائيا في استراتيجيات المواجهة المستخدمة بكثرة بين المسنين المصابين بالسرطان و الأسوياء.

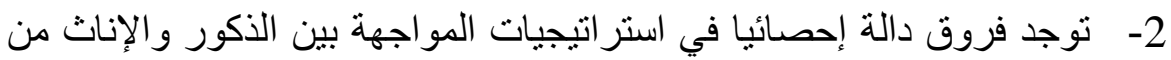
عينة المسنين المصابين بالسرطان. 3- توجد فروق دالة إحصائيا في استراتيجيات المواجهة بين المتزوجين والين وغير المتزوجين من عينة المسنين المصابين بالسرطان. أهمية الدراسة: تتمثل أهمية الدر اسة الحالية في النقاط التالية:

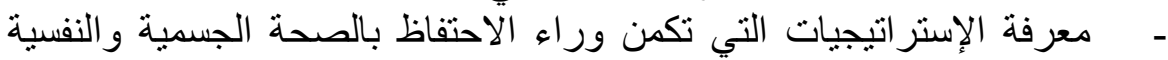
رغم التعرض للضغوط و الاستفادة من هذا في مجال العنات العلاج النفسي.

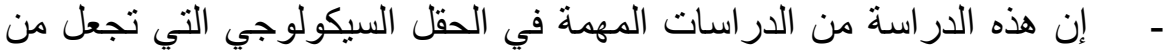

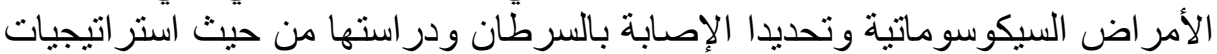

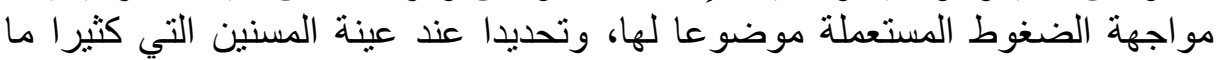
يتقلص محور الاهتمام بها في الدراسات العربية خاصة فيما يتعلق بمتغيري الدراسة.

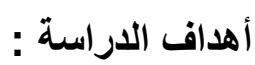

- ـ الكثف عن الفروق بين المسنين المصابين بالسرطان و غير المصابين فيما

يخص استر اتيجيات مواجهة الضغنو الضغوط.

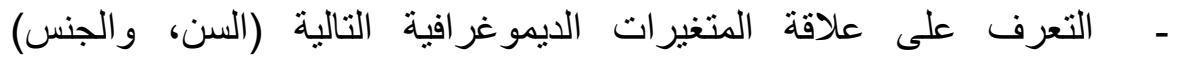
بإستر اتيجيات المواجهة المستعملة من قبل المسنين المصابين بالسرطان. 


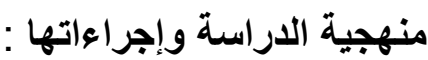

منهج الاراسة : تهدف هذه الدراسة إلى محاولة التعرف على استراتيجيات

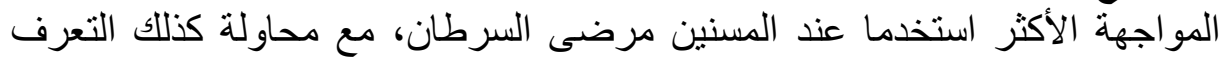

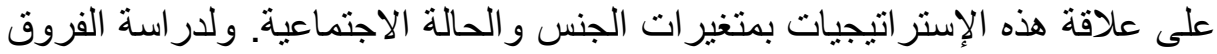

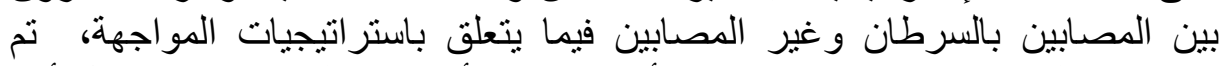

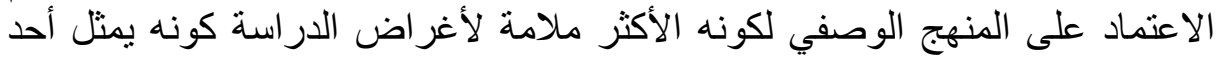

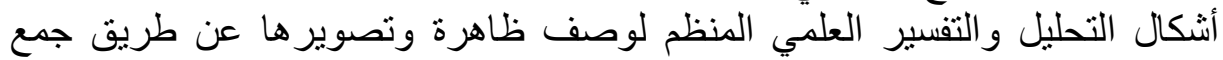

بيانات عنها مقننة و وتصنيفها وتحليلها و إخضاعها للدر اسة دقيقة (5).

$$
\text { عينة الدراسة : }
$$

تضم 100 فرد مقسمة إلى مجموعتين هما المجموعة المريضة (المصابة

بالسرطان) والتي تضم 50 شخصا مسنا ممن يترددون على المؤسسة الإستشفائية

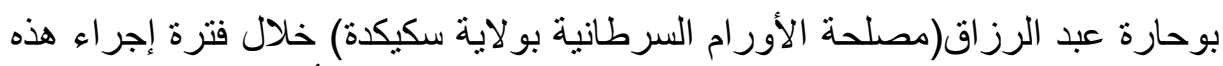

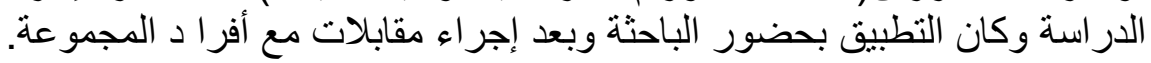

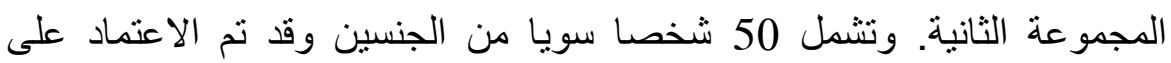

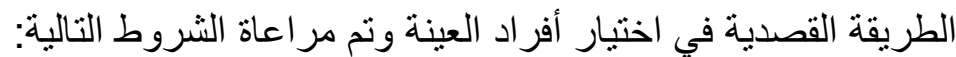

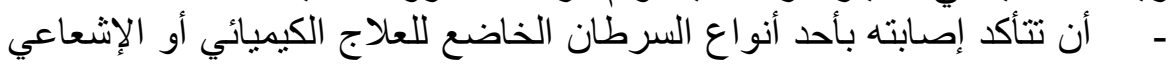
(بالنسبة للعينة المريضة).

- - أن يكون العمر من 60 فما فوق باعتبار الدراسة تهنم بالمسنين و بالنسبة للأصحاء كذلك. - ل أن لاء لأل يكون مصابا بمرض مزمن أو حاد (خاصة السرطان بالنسبة للأصحاء). وينبغي الإشارة إلى أن عينة الأصحاء تم اختيار ها من المجتمع العام. جدول رقم (1): يوضح نوزيع العينة حسب منغيرات السن والجنس والحالة

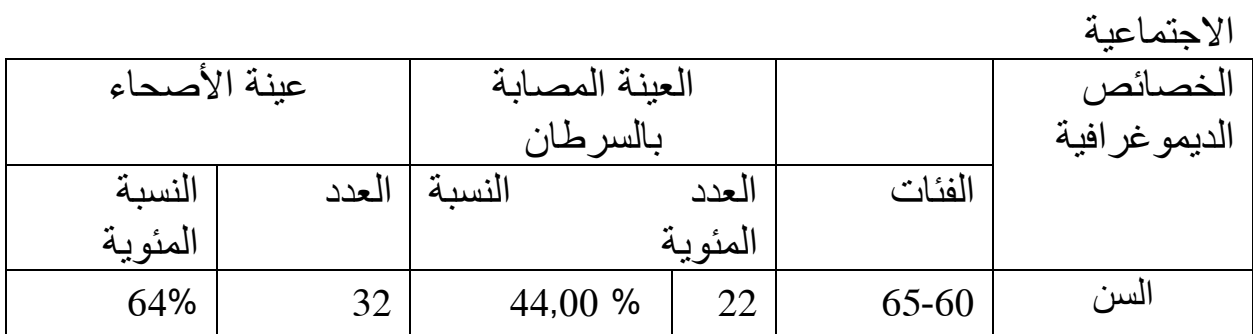




\begin{tabular}{|c|c|c|c|c|c|}
\hline $16 \%$ & 08 & $20 \%$ & 10 & $70-66$ & \\
\hline $6 \%$ & 03 & $16 \%$ & 8 & $75-71$ & \\
\hline $14 \%$ & 07 & $20 \%$ & 10 & من 75 فما & \\
\hline $100 \%$ & 50 & $100 \%$ & 50 & فوق & \\
\hline $76 \%$ & 38 & $32 \%$ & 16 & ذكر & \multirow[t]{3}{*}{ الجنس } \\
\hline $24 \%$ & 12 & \multirow[t]{2}{*}{$68 \%$} & \multirow[t]{2}{*}{34} & \multirow[t]{2}{*}{ أنثى } & \\
\hline $100 \%$ & 50 & & & & \\
\hline $43 \%$ & 77 & $34 \%$ & 34 & متزوج & الحالة \\
\hline $7 \%$ & \multirow[t]{2}{*}{23} & \multirow[t]{2}{*}{$16 \%$} & 16 & \multirow[t]{2}{*}{ غير متزوج } & \multirow[t]{2}{*}{ المدنية } \\
\hline 1000 & & & 50 & & \\
\hline
\end{tabular}

يتضح من الجدول أعلاه رقم (1) بالنسبة للعينة الأولى ( المصابة بالمرض) أن الفئة العمرية الممتدة 60 إلى 65هي التي تسجل العدد الأكبر من المصابين و أصغر نسبة كانت في الفئة العمرية الممتدة من 71 إلى 75 سنة بنسبة 16\%.أما بالنسبة لعينة الأصحاء فقد سجلت الفئة العمرية كذلك الممتدة من 60 إلى $65 \%$ أعلى نسبة تمثيل وهي 64\% و أقل نسبة تمثيل في أفراد العينة كانت في المرحلة العمرية

$$
71 \text { إلى } 75 \text { سنة بنسبة 16\% و } 16 \text { هب }
$$

أما عن متغير الجنس بالنسبة لعينة المرضى فقد كانت نسبة التمثيل \% 32 من الذكور لتكون الإناث الأعلى تمثيلا في العينة بنسبة 68\%. وفيما يخص عينة الأصحاء فقد كان الذكور يمثلون 76\%، و الإناث يمثلون 24\% من أفراد الاد العينة. وبالنسبة لمتغير الحالة المدنية لعينة المصابين بالسرطان فقد كان المتزوجون يمثلون 34 من أفراد العينة وغير المتوجين يمثلون \% 16 و وبالتالي كانوا الأقل تمثيلا.و عن مجموعة الأصحاء فعلى العكس كان الأعلى تمثيلا المتزوجون بـ 77\% والأقل تمثنيلا بـ \% 23 غير المتزوجين.

أداة البحث المستخدمة في هده الدراسة: لقد ثم الاعتماد في إنجاز هده الدراسة على أداة واحدة وهي: مقياس استراتيجيات التعامل مع الضغط النفسي (coping):

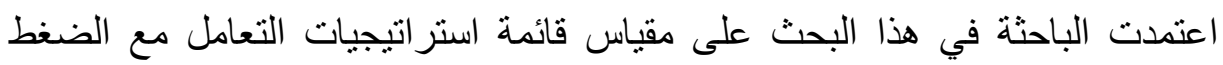


"Vitaliano" " اللباحث "فيتاليانو The way of coping check list (WCCL) و آخرون سنة 1985 ، المكيف من طرف الباحثة "بولهان" Paulhan " وآخرون سنة

وضع لازاروس وفولكمان سنة 1980 مقياس استراتيجيات المواجهة الذي تم تطويره عدة مرات من قبل مصمميه، يحتوي على 67 بندا، تعمل على تقرير

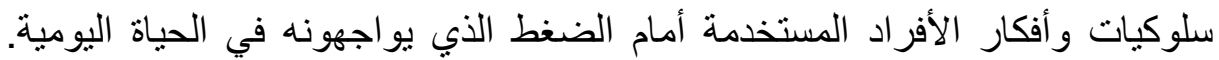
ولقد تم تعديل هذا المقياس من قبل فيتاليانو Vitaliano سنة 1985 حيث قام بتقليص عدد البنود ليصبح 42 بندا.

Cousson et ثم تم تكييف هذا المقياس إلى اللغة الفرنسية من قبل كوسون وآخرون

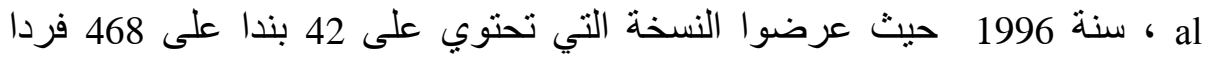

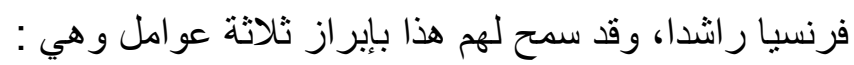

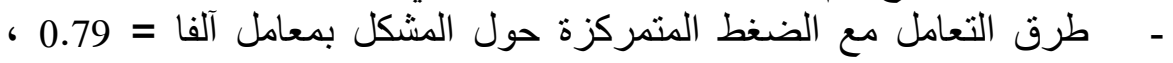
وتشمل 10 بنود هي : 1-22-27-2-

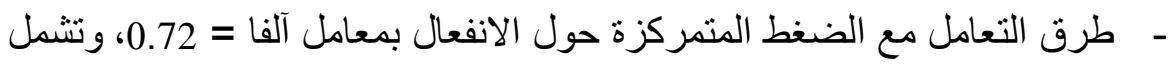

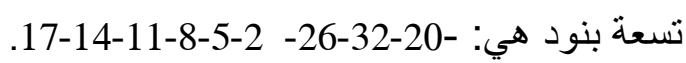

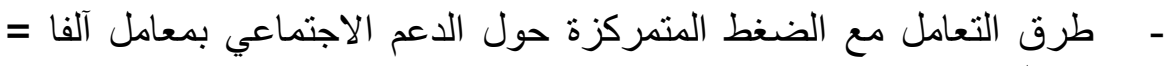

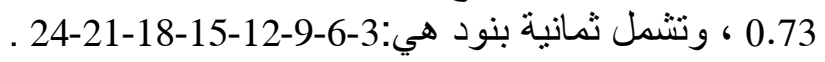

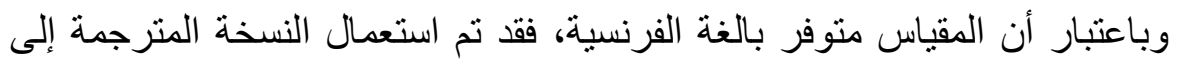

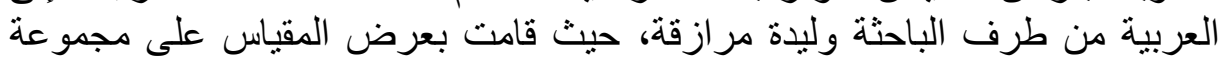

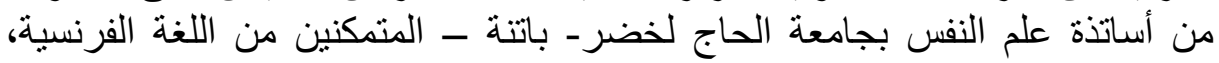

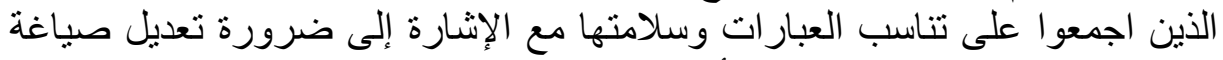

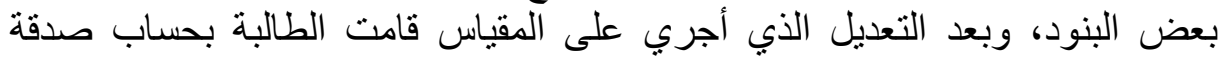
وثباته (6).

\section{المعالجة الإحصائية المستخدمة :}

إن طبيعة هذه الدراسة التي تتناول بالبحث الإخة الاختلافات الموجودة بين عينين

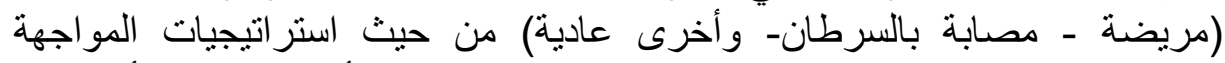

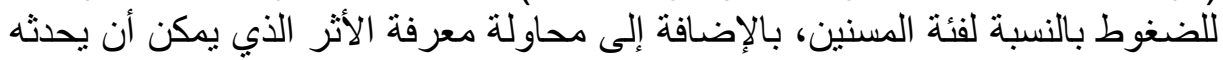

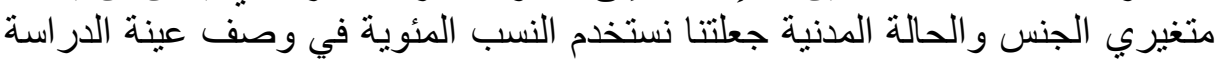

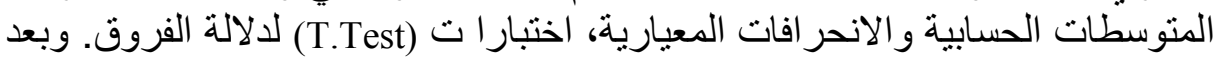




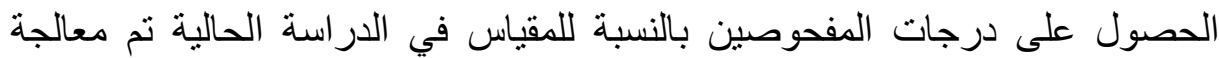

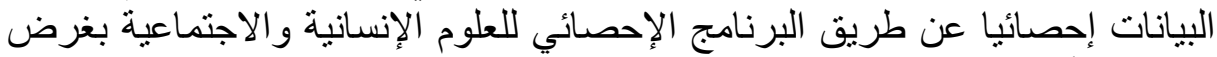

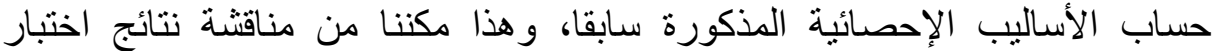
فرضيات الدراسة في العرض الإلب الموالي.

\section{نتائج الدراسة ومناقشتها :}

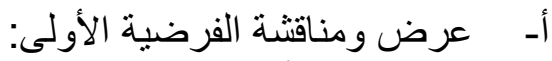

تشير الفرضية الأولى إلى: وجود فروفئ الأفئ دالة إحصائيا بين المسنين المصابين

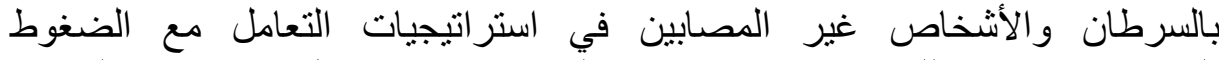

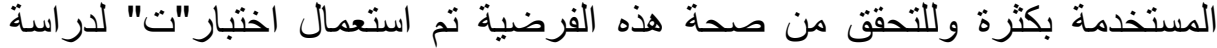
الفروق بين المجموعتين (المصابة بالسرطان و غير المصابة) وتحصلنا على الجدول التالي: - (الفزوف

جدول رقم (02) : يمثل نتائج الفروق الإحصائية بين مجموعة المصابين

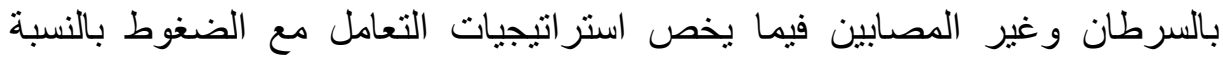

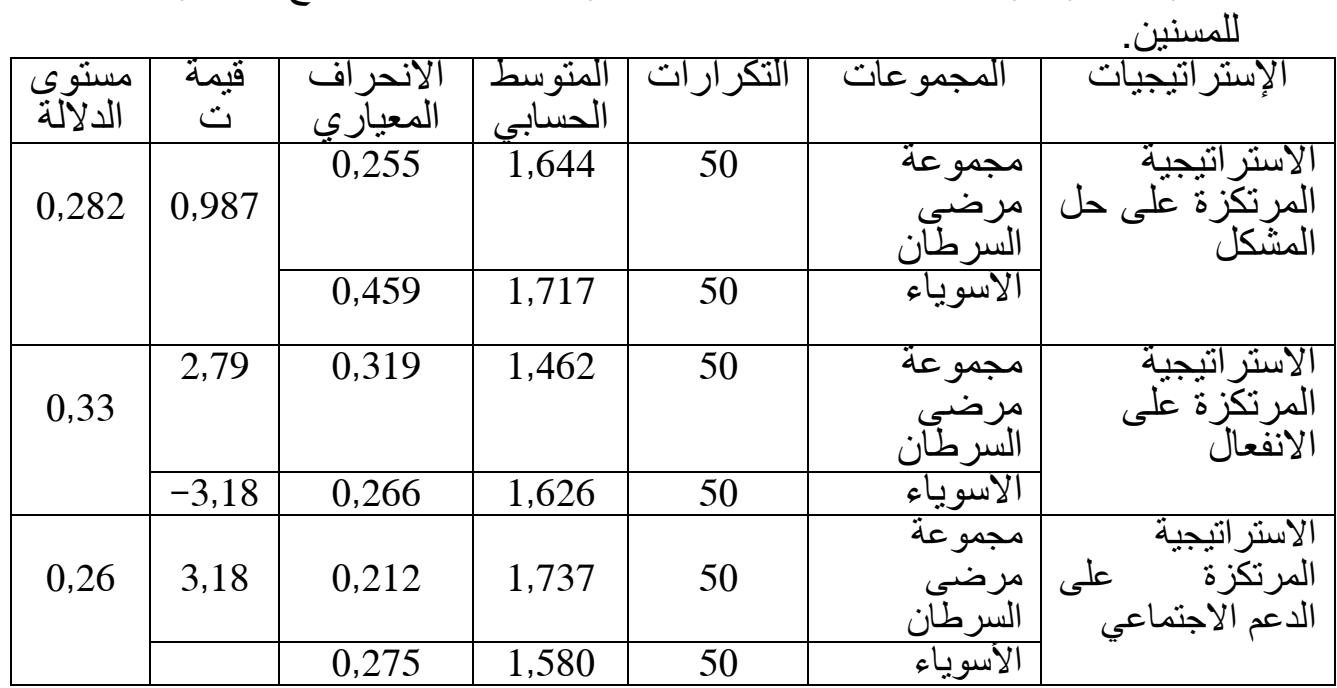

نلاحظ من خلال الجدول رقم (02) أن الفروق في متوسط درجات مجموعة

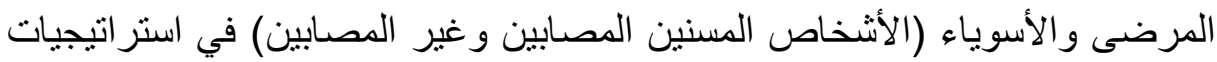

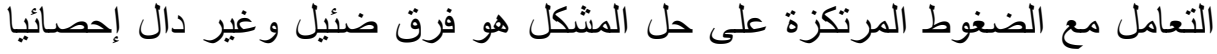

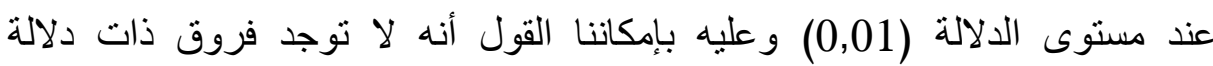
إحصائية بين المصابين بالسرطان وغير المصابين في استعمال الإستر اتيجية المرتكزة 
ونلاحظ من خلال نفس الجدول أن المتوسط الحسابي للمجموعة الخاصة بالمرضى فيما يتعلق بإستر اتجية الانفعال والذي قدره 46،1 أقل من المتوسط الحسابي لمجموعة الجية الأصحاء وهو62،1 وبلغ منوسط الفرق ت (4,691) وهو دال عند المستوى (0,01) وبتالي بإمكاننا استتناج أن هناك فروقا دالة إحصائيا بين المصابين بالسرطان

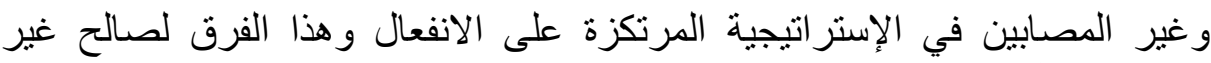

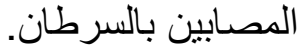

ومن خلال ذات الجدول نلاحظ أن المتوسط الحسابي لمجموعة الأسوياء فيما يتعلق

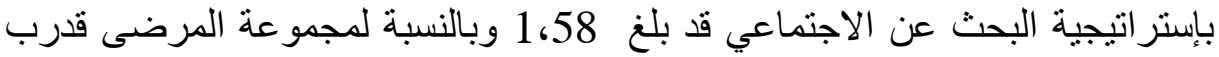
73، 1، ومتوسط الفرق (5.10) و هو فرق دال إحصائيا عند المستوى 01،0 وقد جاء

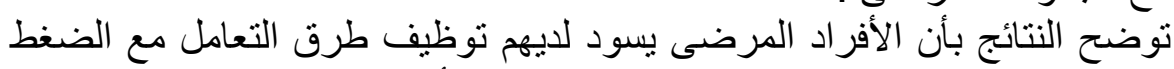

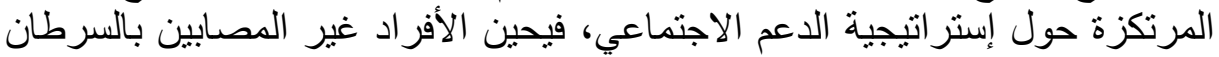

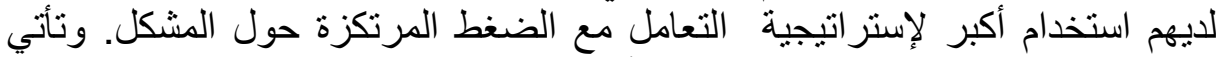

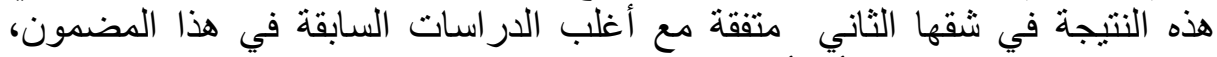

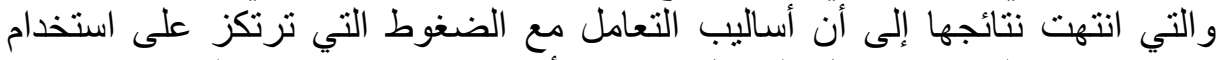

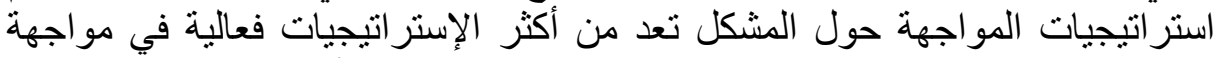

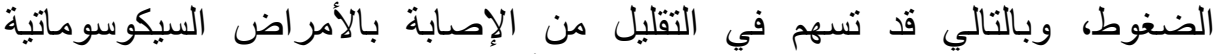

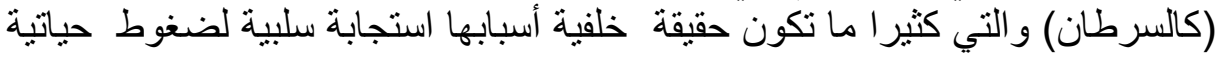

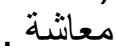

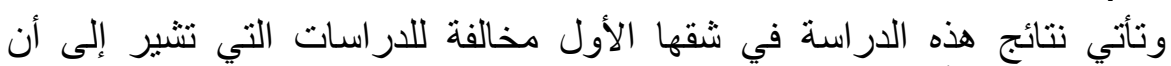

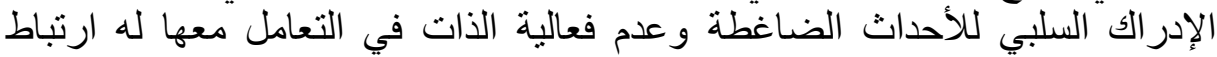

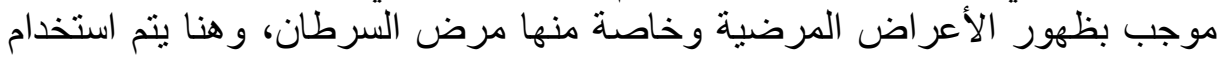

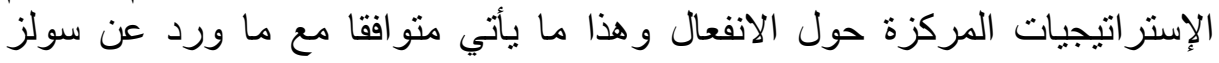

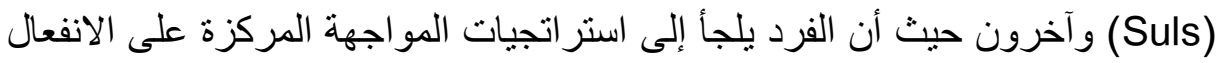

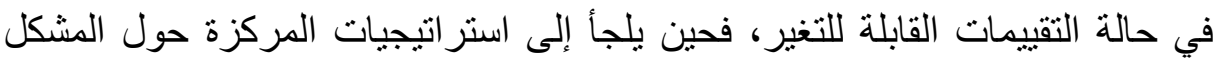
في حالة التقييمات القابلة للتغيير (7). وفي ذات السياق انتهت در اسة لـ كيم يوم سي يو (Kym Yoom Seo Yoo) بكوريا الجنوبية إلى أن إستراتيجية مواجهة الضغوط التها المرتكزة على الانفعال هي الأكثر

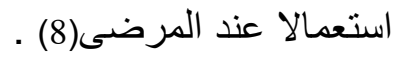

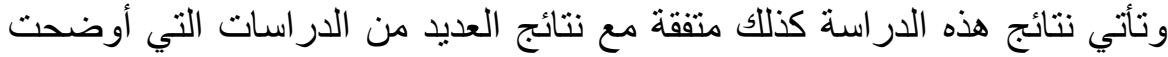

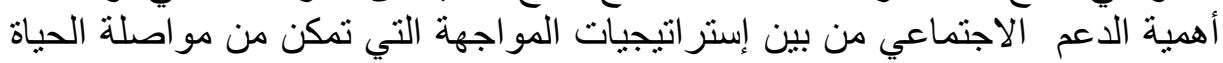


و التعايش مع السرطان( بلاندرمان وشارني 2005، Cheny، Blinderman , شاهاي ، Shahay 2000 زوكا ، بويز وآخرون ،Zucca ,Boys et al 2010) ونذكر هنا بشكل خاص در اسة زوكا وبويز وآخرون، 2010 و التي كانت عينتها مماتلة مع عينة در استنا الحالية (فئة المسنين 60 سنة فما فوق) و التي توصلت نتائجها أن الأشخاص المسنين المتزوجين و الذين لديهم دعم اجتماعي لديهم روح مقاومة عالية بالمقارنة مع

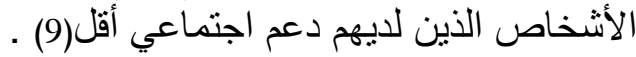

وقد بينت كذلك أحد الدراسات أن الحصول على دعم اجتماعي عالي سمح للنساء

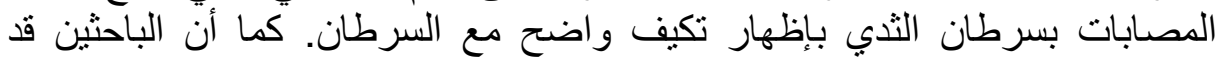

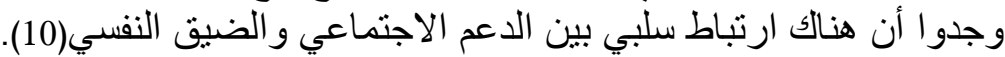

ولا تختلف نتائج در استتا الحالية فيما يتعلق باستعمال إستر اتيجية الدعم الاجتماعي مع ما انتهت إليه دراسة لدانكل- شيتر وزملائه

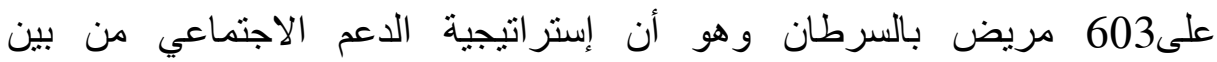

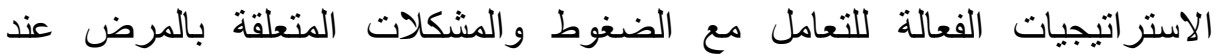

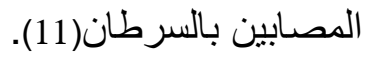

وترى الباحثة أن الأشخاص المصابين بالسرطان و الدين يكونون في مرحلة عمرية

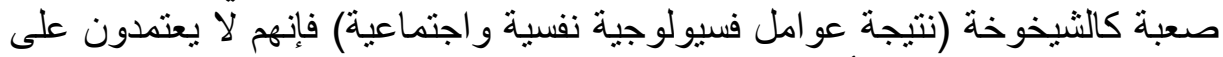

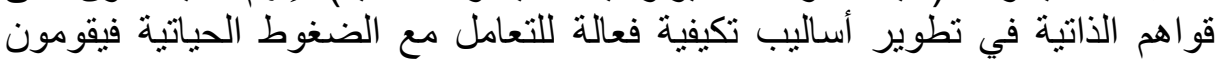

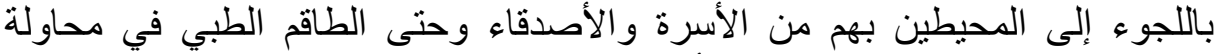

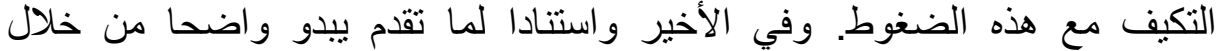

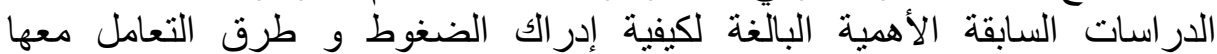

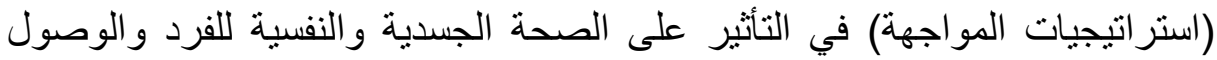
إلى عملية التكيف من عدمها مع البيئة المعاثة.

2- عرض مناقشة نتائج الفرضية الثانية: تثير الفرضية إلى أنه توجد فروق ذات دلالة إحصائية في استر اتيجيات مواجهة الضغوط لدى المسنين المصابين بالسرطان

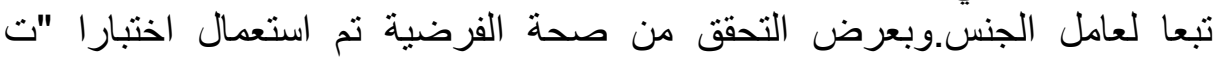
"لدراسة الفروق بين المجموعتين (الإناث والذكور) والنتائج موضحة في في الجدول

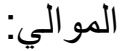


جدول رقم (03) :يوضح الفروق في استراتيجيات مواجهة الضغوط بين المسنين المصابين بمرض السرطان تبعا لمتغير الجنس.

\begin{tabular}{|c|c|c|c|c|c|c|}
\hline الدلالة & قيمة ت & \multicolumn{2}{|c|}{ إناث } & \multicolumn{2}{|c|}{ ذكور } & استر اتيجيات \\
\hline & & الانحر اف & الحسابي & الانحراف & الحسابي & المو اجهة \\
\hline 0.003 & -3.12 & 0,23 & 1,71 & 0,23 & 1,49 & المتمركزة المشكل \\
\hline 0.31 & -1.09 & 0,32 & 1,49 & 0,31 & 1,39 & المتمركزة الانفعال \\
\hline 0.001 & $-3,51$ & 0,15 & 1,80 & 0,25 & 1,59 & الاجولمركز الدعم \\
\hline
\end{tabular}

نلاحظ من خلال الجدول رقم (03): أن متوسط درجات الإستر اتيجية المتمركزة حول المشكل بالنسبة للأكور بلغ 1,49 بانحر اف معياري 0,23 وبالنسبة للإناث فقد الإند بلغ 1,71 بانحر اف معياري 0,23 .

وبلغت قيمة ت المحسوبة 3،12- وهي غير دالة إحصائيا عند مستوى الدلال

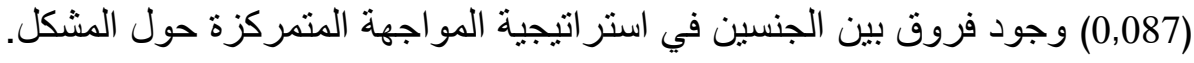
وبلغ منوسط درجات الاستراتيجية المتمركزة حول الانفعال لدى فئرئ الذكور 1,39 بانحراف معياري قدره 0,31 ولدى الإناث بلغ المتوسط الحسابي 1,49 بانحراف معياري 0,32 وكانت قيمة " ت" المحسوبة تساوي 1,09 - و هي دالة إحصائي لإئيا عند

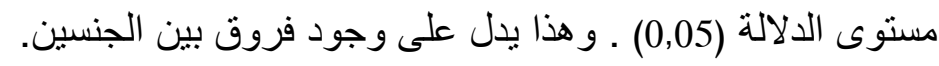
أما متوسط درجات الإستر اتيجية المتمركزة حول الدعم الاجتماعي لدى الذكور بلغ

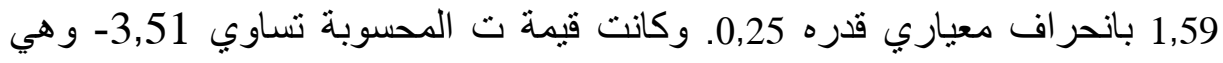

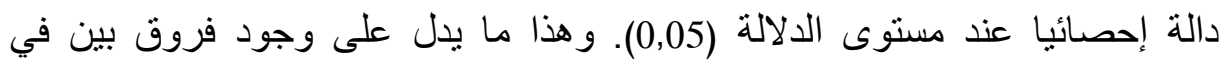
الإستر اتيجية المتمركزة حول الدعم الاجتماعي.

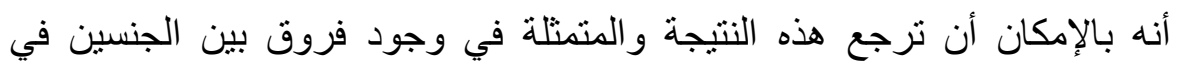

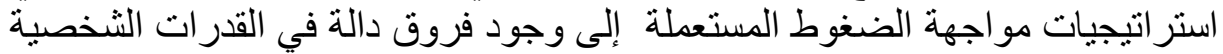

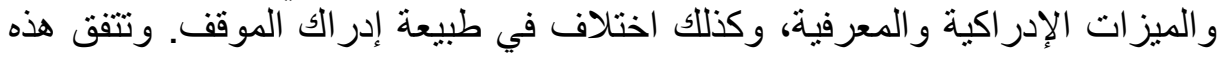

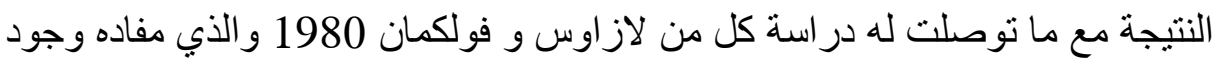
فروق بين الجنسين فيما يتعلق باستر اتيجيات المواجهة للضنغوط لأل المستعملة. 
وتحديدا في أسلوب المواجهة المركز على المشكل لكن لصالح الذكور وهذا ليس

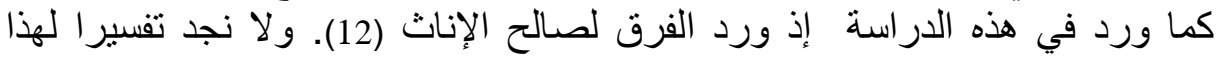
سوى ما أشرنا إليه سابقا هو اختلاف في القدرات الثخصيات و الظروف المحيطة

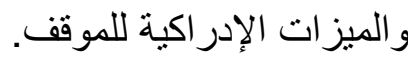

وفيما يتعلق بنتائج إستراتيجية الانفعال فنجد الفارق لصالح الإناث وهذا ما يرد

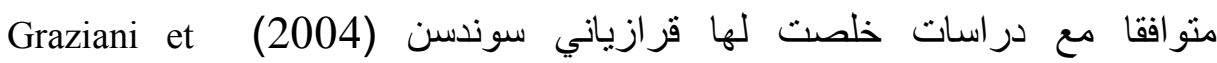
و التي مفادها أن الإناث يوصفن بأنهن يستعملن أكثر الإستراتيجيات المتمركزة حول الانفعال في مواجهة الضغوط الإنان يوط (13).

وكثفت نتائج هذه الدراسة أن هناك تأثثير للعامل الجنس في استخدام إستر اتيجية

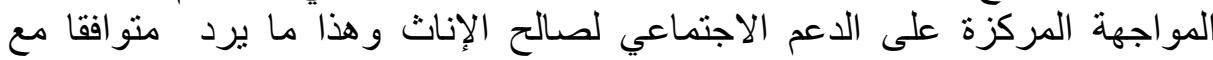

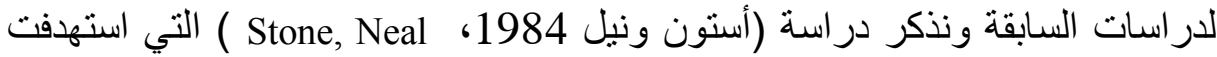
التعرف على أساليب المواجهة في الموافق الضاغطة لكلا الجنسين (14) وتختلف نتائج هذه الدراسة مع دراسة وليدة مرازقة (2007) التي لم تتوصل إلى وجود فروق بين

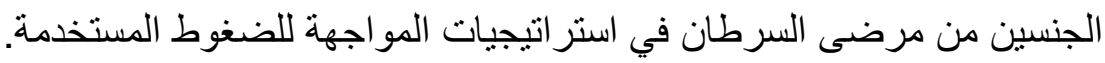

\section{عرض ومناقشة الفرضية الثالثة :}

تشير الفرضية الثالثة إلى أنه توجد فروق ذات دلالة إحصائية بين المتزوجين

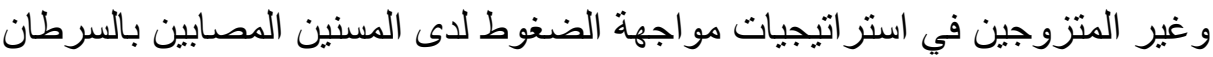

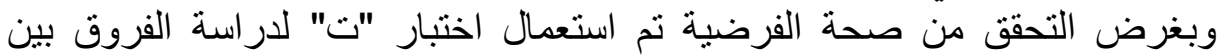
المجمو عتين (المتزوجين وغير المتزوجين).

جدول رقم (04): يوضح الفروق في استر اتيجيات مواجهة الضغوط بين المسنين المصابين بالسرطان تبعا لمتغير الحالة المدنية.

\begin{tabular}{|c|c|c|c|c|c|c|}
\hline \multirow[t]{2}{*}{ الدلالة } & \multirow[t]{2}{*}{ قيمة ت } & \multicolumn{2}{|c|}{ غير متزوجين } & \multicolumn{2}{|r|}{ متزوجون } & \multirow{2}{*}{ المتر اتيجيات } \\
\hline & & الالحعر اف & الحستوسي & الالحعر اف & الحستوسي & \\
\hline غير دالة & 0,23 & 0,28 & 1,63 & 0,24 & 1,65 & حول المشكركل \\
\hline غير دالة & 1,77 & 0,34 & 1,57 & 0,29 & 1,40 & حول الانفعال \\
\hline غير دالة & 0,49 & 0,14 & 1,65 & 0,15 & 1,59 & الاجنماعي الدمرة \\
\hline
\end{tabular}


يتضح من الجدول رقم (04) عدم وجود فروق دالة إحصائيا في استراتيجيات

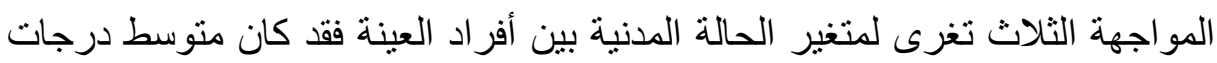

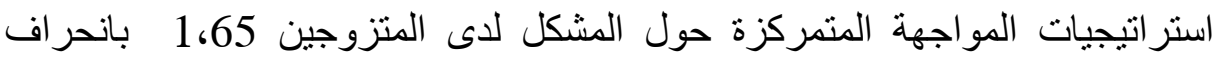
معياري قدره 0,28 وبلغت قيمة ت المحسوبة (60،0) المحسوبة وهي قيمة غير دالة

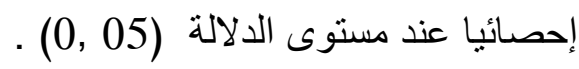

وكان منوسط درجات استر اتيجية المواجهة المرتكزة حول الانفعال لدى المتزوجين

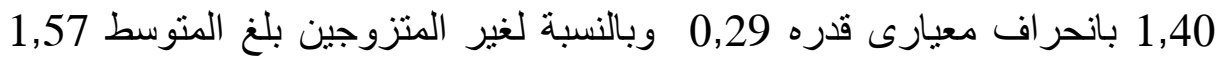
بانحراف معياري 0,34 وكانت قيمة ت المحسوبة (1,77) وهي قيمة غير دالة إحصائيا. وكان منوسط درجات الإستراتيجية المرتكزة على الدعم الاجتماعي لدى الدى

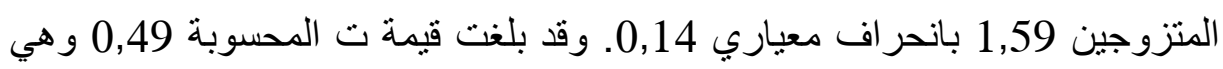
قيمة غير دالة إحصائيا.

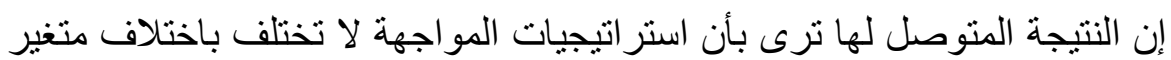

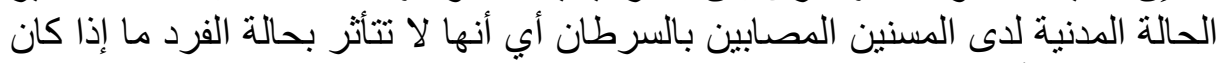

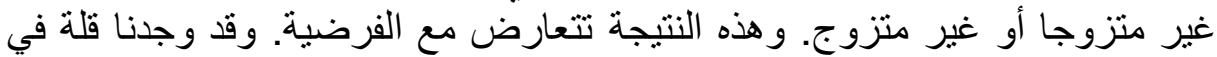

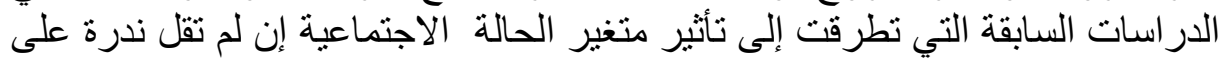

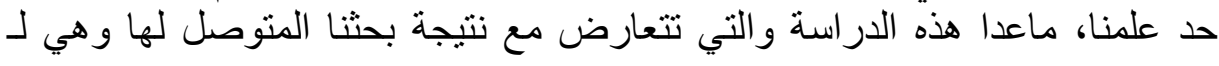

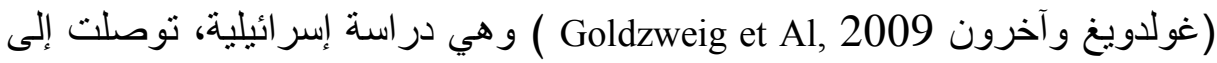

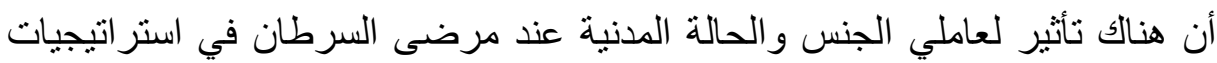
المواجهة للتعامل مع الضغط لئل الضير (15).

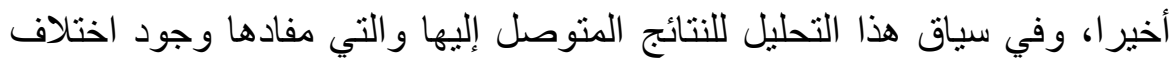

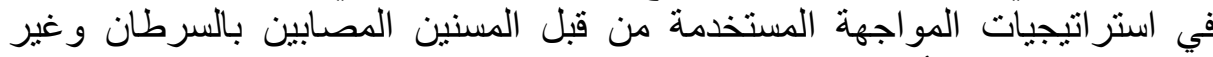

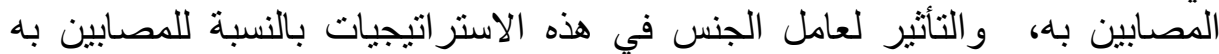

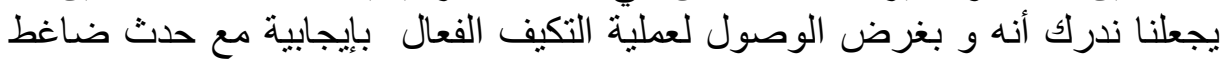

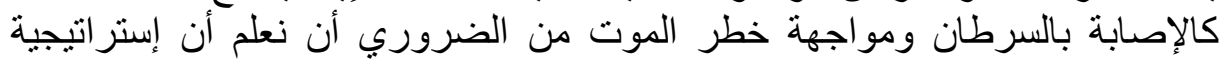

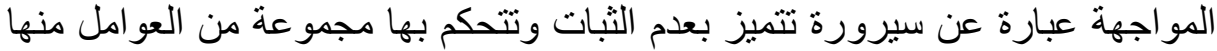

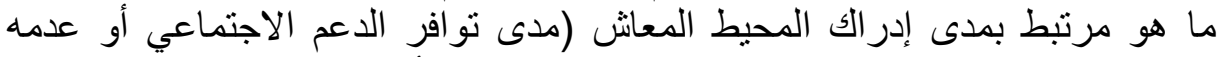

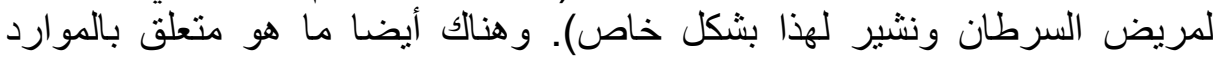

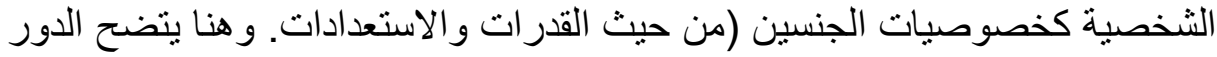
الهام لإستراتيجية المواجهة وما تتضمنه من تصورات وتوقعات في التحكم في المرض و إيقاف تطوره. 
1- بشير معمرية، عبد الحميد حزار(2009)،الاضطرابات الجسمية والنفسية لدى المسنين،

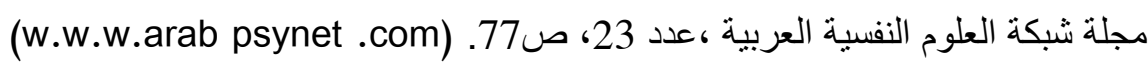
2-وليدة مرازقة (2009) مركز ضبط وعلاقته بإستراتيجيات المواجهة لدى مرضى السرطان مذكرة ماجستير غبر منشورة جامعة باتتة، ص3.

3-Laurence Janot, Bergugnant Nicole Rascale(2008), le stress des enseignants ,Armand colin, paris ,p39 .

4 - أحمد عبد مطيع الثخابنة، (2010)، التكيف مع الضغوط النفسية دراسة ميدانية، دار

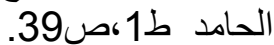

5- سامي محمد ملحم،(2007)، مناهج البحث في علم النفس دار المسيرة ، الأردن، ص37.

6- وليدة مرز اقة، مرجع سابق،ص111.

7- مزياني فتيحة (2007) أثر مصادر الضغط المهني واستراتيجيات المقاومة المعبرية

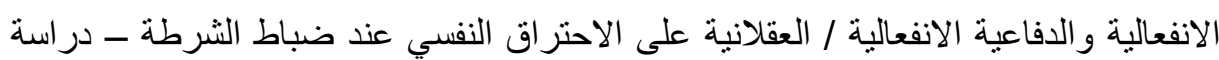

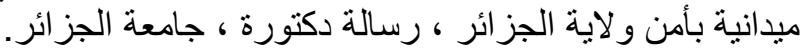

8-Goreti Maria, (2012), Sentiment de finitude de vie et de coping chez patient face l'annonce d'un cancer digestif, mémoire Master non publié, université de Lausanne.

9- Op.cit, p40 .

10-Carole Zozaya ,(2011), déterminants des trajectoires de détresse pendant la première années qui suit l'annonce d'un cancer primitif ou récidivant. Thèse de doctorat, université Bordeaux 2.

11- شيلي نايلور(2008)، ترجمة وسام درويش بريك، فوزي طعيمة داود، دار الحامد، عمان، ط1 . - مان

12- أمل سليمان تركي العتري 2006، أساليب مواجهة الضغوط بالئ عند الصحيحات

و المصابات بالاضطر ابات النفسجسية، دراسة مقارنة رسالة ماجستير غير منشورة، جامعة

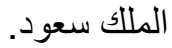

13- و اكلي بديعة (2013) ، استر اتيجيات المواجهة المكتئبين، رسالة دكتور راه غير منشورة

جامعة سطيف. - ماكي

14- عبد الضريبي،(2010)، أساليب مواجهة بعض الضغوط المهنية وعلاقتها ببعض المتغير ات، مجلة جامعة دمشق، مجلد 26، العدد الرابع.

15-Goreti Maria, Op.cit, pp 41-42 . 